\title{
VALPARAÍSO, O LA LOCA GEOGRAFÍA DEL DESEO: INFANCIA QUEER Y \\ CRUISING HOMOSEXUAL EN QUINCE POEMAS DIRECTOS (1936) DE BENJAMÍN SUBERCASEAUX
}

\section{VALPARAÍSO, OR THE CRAZY GEOGRAPHY OF DESIRE: QUEER CHILDHOOD AND HOMOSEXUAL CRUISING IN QUINCE POEMAS DIRECTOS (1936) BY BENJAMÍN SUBERCASEAUX}

\author{
Ignacio Sánchez Osores \\ University of Notre Dame, Estados Unidos \\ isanche2@nd.edu
}

\begin{abstract}
Resumen:
En este artículo se analiza Quince poemas directos (1936) de Benjamín Subercaseaux, acaso el primer poemario homoerótico de la poesía chilena. En particular, se propone que el poeta incorpora dos figuras clave en el imaginario queer local: el cruisser -hermano errado del flâneur- y el niño homosexual. Dado lo anterior, se indaga en cómo estas figuraciones polemizan directamente con el imaginario heteropatriarcal del Frente Popular en tanto promotor de una masculinidad hegemónica y una política reproductiva de la nación que excluyen a las subjetividades sexo-disidentes.
\end{abstract}

Palabras claves: poemario homoerótico, cruisser, niño homosexual, Frente Popular, imaginario heteropatriarcal

\begin{abstract}
:
This article analyzes Quince poemas directos (1936) by Benjamín Subercaseaux, perhaps the first homoerotic collection of poetry in Chilean poetry. In particular, it is proposed that the poet incorporates two key figures in the local queer imaginary: the cruisser - flâneur's wrong brother- and the homosexual child. Given the above, it is investigated how these figurations directly polemicize with the heteropatriarchal imaginary of the Frente Ppopular as promoter of a hegemonic masculinity and a reproductive policy of the nation that exclude sex-dissident subjectivities.
\end{abstract}

Key words: homoerotic collection, cruisser, homosexual child, Frente Popular, heteropatriarchal imaginary.

Recibido: 15 de abril de 2021

Aceptado: 07 de junio de 2021

\section{Introducción}

Alejandro Jodorowsky señala que en su juventud la homosexualidad no era una cuestión problemática. Por el contrario, reconoce que, entre los suyos, las prácticas 
Dossier. Ignacio Sánchez Osores. "Valparaíso, o la loca geografía del deseo: infancia queer y cruising homosexual en Quince Poemas Directos (1936) de Benjamín Subercaseaux".

homoeróticas eran frecuentes y conocidas por todos. Me detengo, a continuación, en un pasaje en que el escritor describe y testimonia los lugares de encuentro o cruising criollo:

Los homosexuales descendían a Valparaíso a las pistas de baile a buscar marineros y obreros y entre la gente del pueblo, eso era común. La gente del pueblo eran los activos. Además iban a la plaza Yungay, cerca de Cummings. Para la fiesta del "roto chileno" iban todos los homosexuales. Iban para cogerse al pueblo. Esta era una fiesta homosexual. Otros iban a Horcón; donde los pescadores les hacían favores... (Cit. en Jouffe s.p).

El testimonio de Jodorowsky es relevante no solo porque hace alusión a lugares de cruising criollo, sino porque también enuncia que estos encuentros son entre individuos provenientes de clases distintas. En el fragmento se opone al hombre burgués y al hombre del pueblo: al primero se lo caracteriza como aquel que va en búsqueda del segundo para satisfacer sus deseos y apetitos sexuales. El hombre del pueblo (colectivo conformado por marineros, obreros y rotos) es quien desempeña el rol activo en estas prácticas proscritas, mientras que el homosexual burgués es aquel que es cogido y que, por tanto, desempeña el rol pasivo. La descripción de Jodorowsky parece decirnos indirectamente que el pueblo, figura protagónica de la literatura de la Generación del 38, a pesar de participar de encuentros homoeróticos no es, sin embargo, homosexual, pues es un agente que al ejercer la penetración se desmarca de esa etiqueta. El pueblo no puede ser despojado de su virilidad, esto es, del lugar central que encarna no solo en los relatos de izquierda, sino además en el metarrelato de la identidad nacional.

Benjamín Subercaseaux, escritor de la élite nacional, conocido por su clásico ensayo Chile o una loca geografía (1940) se adentra en las prácticas homoeróticas descritas por Jodorowsky y, precisamente, en Quince poemas directos (1936), un poemario casi desconocido en la literatura chilena, se hace cargo poéticamente de aquellos homosexuales burgueses que descienden a Valparaíso para encontrarse con el pueblo; instalando en el campo literario de la época, acaso, el primer poemario homoerótico. Subercaseaux, consciente de la presencia omnipresente de lo queer en su proyecto estético-político no vacila en excusarse por la atención que el "sexo" le merece:

Se me dirá una vez más que me complazco en poner en delectación morbosa en las cuestiones del sexo. Pero, me pregunto, ¿cómo podría 
eludir este resorte oculto y profundamente disimulado que es la razón principal de tantas actitudes-inocentes-al parecer que condicionan la vida íntima de los barrios santiaguinos? (122)

El escritor "baja del Olimpo" e inventa una ciudad homoerótica que abre sus puertas a una nueva subjetividad poética: el homosexual, dado que el "resorte oculto y profundamente disimulado" de la homosexualidad no puede ser eludida, de ahí que sus Quince poemas sean caracterizados como "directos", es decir, exentos de ocultamientos. En efecto, en este poemario la subjetividad homosexual aparece de manera audaz y desenfadada, acaso celebratoria, sin florilegios que alegoricen o la insinúen como pecado innombrable por primera vez en la poesía chilena. El poeta, como veremos más adelante, se sitúa de manera estratégica, pero marginal en la tradición poética canónica en tanto aprehende lo que le sirve de esta y desecha aquello que no contribuye a su proyecto estético. En el poemario se exhibe el primer cruisser de la literatura chilena, marcando un hito en la tematización de las prácticas sexuales queer, figura en la que ahondaremos más adelante y que será retomada posteriormente, por los poetas de la Generación de los Náufragos, también conocida como Generación de los 90 (Antonio Silva, Francisco Casas, Pedro Montealegre) y por narradores y cronistas como Pedro Lemebel. He aquí lo intrépido del gesto: Subercaseaux no oculta mediante artilugios retóricos la homoerótica de la ciudad de Valparaíso porque su propósito es precisamente ponerla en escena.

No obstante, poco y nada se conoce sobre Benjamín Subercaseaux (1902-1973), escritor, investigador y diplomático, mayormente, conocido por su trabajo ensayístico. Su vasta producción escritural, entre la que cuentan más de una veintena de textos, abarca todos los géneros (novela, poesía, teatro, ensayo). A pesar de la variedad y calidad de su obra y de que, incluso, recibió el Premio Nacional de Literatura en 1963, la crítica ha sido bastante haragana ${ }^{1}$. La recepción de su trabajo escritural se ha centrado, fundamentalmente, en su ensayo Chile o una loca geografia (1940), reeditado en distintos momentos y que ha sido considerado como clave en la configuración de la identidad chilena, en tanto "lectura de Chile" (Calderón s.p) o "alegoría nacional” (Hozven 211). Junto a este texto, han venido a tener mejor suerte, en los últimos años Niño de lluvia (1938; 1942), debido al auge de los estudios queer (Sutherland 2001) y de las narrativas autobiográficas (Amaro 2018) y,

\footnotetext{
${ }^{1}$ Remito a la expresión utilizada por Ángel Rama para catalogar a la crítica brunetiana en el texto "La condición humana".
} 
Dossier. Ignacio Sánchez Osores. "Valparaíso, o la loca geografía del deseo: infancia queer y cruising homosexual en Quince Poemas Directos (1936) de Benjamín Subercaseaux".

asimismo, desde un enfoque en los imaginarios visuales (Chiuminatto y del Río) se ha destacado Tierra de océano (1946). Por último, desde una mirada sexo-genérica vale la pena mencionar el trabajo pionero de Ramón García Castro (1996) sobre el ensayo antropológico Santa Materia (1954). Entre sus obras merecedoras de premios destacan, las ya nombradas Chile o una loca geografia (Premio Municipal de Literatura de Santiago 1941) y Tierra de océano (Premio Municipal de Literatura de Santiago 1947). Y entre las más olvidadas, Jemmy Button (Premio Atenea 1950) y Los execrables harapientos (Premio Camilo Henríquez 1952).

\section{Benjamín Subercaseaux y su relación torcida con la tradición poética chilena}

Benjamín Subercaseaux, el iniciador de la genealogía queer de la poesía chilena, no puede y no quiere hermanarse ni establecer lazos fraternales ni comunitarios con sus compañeros de la Generación del $38^{2}$, debido a que estos comulgan con valores e idearios que expulsan al sujeto homosexual, pues este complica la anatomía de la lucha que persigue el proyecto estético-político del Frente Popular. Subercaseaux sabe de la bastardía, exclusión y consecuente marginación del campo cultural de la subjetividad homosexual. Por tanto, más que optar por una política integracionista no cuestionadora, elige comenzar a elaborar su propio contrarrelato para polemizar con la tradición poética chilena, pues el canon, formado por sus padres literarios, le ha dado la espalda. En este contexto, propongo que el poeta opta por un ejercicio de desidentificación ${ }^{3}$ poética. Me refiero a un conjunto de diversas estrategias estético-políticas adoptadas por escritores y escritoras para desplazarse con relativa autonomía e insertarse (in)cómodamente, y con ciertos resguardos, en el campo literario. De esta manera, la estrategia de la desidentificación es análoga a una escena teatral, toda vez que los sujetos queer entran y salen sin mayores aspavientos del gran escenario que es la tradición literaria; acudiendo a la variedad de la utilería (arsenal retórico) y a distintos gestos o movimientos (imagen y proyección autorial) para performar sus roles.

\footnotetext{
${ }^{2}$ A pesar de que en términos estrictos Benjamín Subercaseaux no pertenece a la denominada Generación del 38, hemos optado por vincularlo libremente a esta por cuanto su proyecto estético-político dialoga polémicamente con la obra de los autores de esta generación y armónicamente con los poetas homosexuales de esta: Luis Oyarzún y Jorge Cáceres.

${ }^{3}$ Adopto esta categoría desde los estudios de José Esteban Muñoz en torno los subjetividades queer de color, particularmente, desde una óptica performática que aquí es traslada a un ámbito literario.
} 
Los sujetos que se desidentifican polemizan desde adentro con la tradición poética, pero sin suscitar el encono y rechazo de sus árbitros (escritores heterosexuales, críticos, periodistas). Estos politizan sus movimientos, ubicándose, distanciándose y reubicándose, simultáneamente, en los espacios de poder. Son los aprendices díscolos que conocen, aprenden y reproducen las corrientes poéticas hegemónicas, pero al mismo tiempo que las reconocen, las desaprenden y producen sus propios desplazamientos, generando, por tanto, sus propias contracorrientes. Sin embargo, la erección de una contracorriente no llega a instituirse como totalizante e inamovible ya que su constitución no es otra cosa que un simulacro. En efecto, el ejercicio desidentificatorio se realiza en un entre-corrientes, es decir, un terreno liminal e intersticial o, en términos literarios, entre la tradición y la ruptura. El carácter fronterizo y la indeterminación del ejercicio desidentificatorio faculta, en definitiva, una serie de desplazamientos de géneros sexuales/textuales.

Subercaseaux en Quince poemas directos (1936) realiza un ejercicio desidentificatorio en tanto entra y sale de los registros y tendencias poéticas canonizadas, atrayendo para sí aquello que le permite enunciar una voz queer. El escritor homosexual no desecha la tradición poética chilena, sino más bien la queeriza, esto es, se apropia de ella a través de citas, parodias, estilizaciones y polémicas, apartándose del imperativo docilizador de las codificaciones estéticas, pero desplazándose en y con ellas estratégicamente. De este modo, el poeta crea un poemario que se resiste a clasificaciones literarias ya que entiende que asimilarse a una de estas implica amoldarse a categorizaciones estáticas y reduccionistas. En efecto, se mueve en un entre-corrientes permanente que le otorga relativa autonomía en un campo literario en el que cunde el "pánico homosexual" (Sedgwick 27). Ni modernista rezagado, ni posmodernista ni vanguardista: el poeta de Quince poemas directos (1936) es ninguno y todos a la vez. Así, logra desasirse de caracterizaciones homogeneizantes; él es un poeta que juega a transitar entre estéticas diversas, connotando con ello la movilidad y heterogeneidad de los géneros sexuales/textuales.

La poetización de la ciudad moderna de Valparaíso, desde una mirada masculina, aparece como antecedente en el poemario Azul (1888) del escritor modernista Rubén Darío. Me interesa la sección“Álbum porteño" y, particularmente, el poema en prosa "En busca de cuadros" toda vez que resulta elocuente para pensar la reescritura poética que más tarde 
Dossier. Ignacio Sánchez Osores. "Valparaíso, o la loca geografía del deseo: infancia queer y cruising homosexual en Quince Poemas Directos (1936) de Benjamín Subercaseaux".

realizará Benjamín Subercaseaux en clave queer. Darío en este poema-cuadro da cuenta de una nueva mirada sobre la modernización portuaria y la emergencia de un nuevo sujeto que la habita en sus contradicciones, esto es, el flâneur:

Sin pinceles, sin paleta, sin papel, sin lápiz, Ricardo, poeta lírico incorregible, huyendo ${ }^{4}$ de las agitaciones y turbulencias, de las máquinas $y$ de los fardos del ruido monótono de los tranvías [...] Abajo están las techumbres de Valparaíso que hace transacciones, que anda a pie como una ráfaga, que puebla los almacenes e invade los bancos, que viste por la mañana terno crema o plomizo, a cuadros, con sombrero de paño, y por la noche bulle en la calle del Cabo con lustroso sombrero de copa, abrigo al brazo y guantes amarillos, viendo a la luz que brota de las vidrieras los lindos rostros de las mujeres que pasan. [...] (155).

El flâneur de Darío se solaza recorriendo la ingente topografía moderna de Valparaíso generando un nuevo sensorium y una nueva mirada que privilegia los cuerpos femeninos; Subercaseaux, reescribe esta ciudad, pero torciendo sus significantes. El poeta queeriza el paisaje portuario distanciándose de poéticas anteriores, toda vez que la ciudad moderna y sus habitantes son descritos mediante metáforas homoeróticas. El espacio no es expuesto desde una matriz naturalista ni modernista, aunque aparentemente, parezcan estas ser los anteojos con los que mira el poeta. Estamos frente a la mirada de un sujeto burgués, un dandy, quien goza cual voyeur, de los cuerpos sudorosos de obreros y marinos que recorren la ciudad.

Benjamín Subercaseaux en su poema "Arte poética" realiza un ejercicio en el que se desidentifa de la tradición literaria canónica nacional que va desde el modernismo (Rubén Darío), el posmodernismo inicial de Carlos Pezoa Véliz y Gabriela Mistral (Desolación) y los vanguardismos (Vicente Huidobro, Pablo Neruda, Pablo de Rokha) muy en boga en el momento de publicación de Quince poemas directos (1936). Subercaseaux abre el poema con un apóstrofe dirigido a la poesía en tanto institución, siguiendo la retórica clásica y anquilosada de los poetas románticos y no sin un dejo de ironía: ““OH, profunda poesía, tú, mi vida y mi pasión"'/Aquí tienes buen amigo, /un modelo de elección" (63). La ironía ("un modelo de elección") presente en estos versos permite caracterizar la “desidentificación” de la voz lírica, pues entra en un registro codificado de la enunciación

\footnotetext{
${ }^{4}$ Las cursivas son mías.
} 
poética (se identifica), pero simultáneamente sale de este registro (se contraidentifica). El escritor propone en su manifiesto la figura del poeta díscolo quien invita a un tú mentado como "amigo", probablemente, aprendiz de poeta, a renunciar a la tradición canónica de la poesía chilena. El primer autor del canon, en el que este particular "amigo" no debe detenerse, es Rubén Darío:

Le siguen otros como claros clarines
que atruenan el aire su canción;
princesas tristes con "no me olvides"
jacintos, tulipas, y rimas en "on" (63).

La voz poética parodia la poesía modernista del poeta de Azul (1888), estética que en su herencia parnasiana y simbolista pone atención, por ejemplo, en la musicalidad y en lo sinestésico. Subercaseaux cita significantes de poemas conocidos de Darío como "claros clarines" ("Marcha triunfal"), "princesas tristes" ("Sonatina"). El poeta imita la métrica modernista (tipo de versos, rima) para mostrarle al tú que no vale la pena detenerse en los artificios retóricos del modernismo: "No se detenga en ellos, amigo..." (63). El exceso verbal y la aristocracia estilística no parecen interesarle demasiado a la voz lírica, aun cuando para escritores sexo-disidentes como Julián del Casal, estos elementos constituyeron la base de una retórica que permitió articular deseos proscritos.

La segunda estética parodiada por Subercaseaux es el posmodernismo inicial de Gabriela Mistral, presente, sobre todo, en su primer poemario Desolación (1922), en el que aún se advierten resabios tardorrománticos y modernistas. La voz poética cita mediante significantes como "heridas abiertas", “frutos enormes", "pulpa de su amor" el léxico presente en los poemas más patéticos de Mistral (e.g. "Nocturno"). El léxico mistraliano de Desolación caracterizado por un registro melodramático y un tono religioso es abandonado, toda vez que a Subercaseaux le interesa centrarse en una retórica sexual más que amorosa. En consecuencia, el poeta le sugiere a su "amigo", por tanto, que tema a la poesía posmodernista:

Témele a sus frutos enormes y a sus heridas abiertas, a sus carnes desgarradas y a la pulpa de su amor (65). 
Dossier. Ignacio Sánchez Osores. "Valparaíso, o la loca geografía del deseo: infancia queer y cruising homosexual en Quince Poemas Directos (1936) de Benjamín Subercaseaux".

Finalmente, Subercaseaux se detiene para parodiar los vanguardismos de los tres poetas que junto con Gabriela Mistral integran el canon poético nacional: Vicente Huidobro, Pablo Neruda y Pablo de Rokha, respectivamente. De Huidobro, el poeta, por un lado, rescata significantes del vanguardismo cosmopolita o modernólatra presente en poemarios como Horizon carré (1917) y Ecuatorial (1918): “mire, amigo,/ la hélice de cristal se sumerge ya/ en el avión del viento. No me deje [...]" (64). De Neruda, por otro lado, cita la etapa residenciaria de su "poesía sin pureza", reconocible en significantes de poemas como "Ritual de mis piernas", "Entrada a la madera" y "Apogeo del apio": "No los confundas con los que dicen: "Los pelos de mis piernas, alambres profundos, perforan la madera del apio en flor" (64). Y, por último, de Pablo de Rokha alude la vanguardia de carácter ruralista presente en su poesía: “Témele, también, a esas vacas perdidas/ que cantan furiosas [...]" (64). La lengua de la vanguardia encarnada en los poetas del canon nacional no le sirve para poetizar los desvíos sexo-genéricos pues es eminentemente masculinista y patriarcal.

El poeta de Quince poemas directos (1936) mediante el ejercicio desidentificatorio, es decir, reconociendo la tradición (identificación) y distanciándose de ella por medio de parodias (contraidentificación) logra enunciar la declaración poética deconstructiva de su poesía. Subercaseaux, cual pupilo díscolo, lee y conoce el canon de la poesía chilena, pero lo rechaza, pues la lengua oficial de las estéticas hegemónicas parecen no servirle del todo para poetizar sus deseos homoeróticos. El poeta mucho antes que Nicanor Parra en Manifiesto (1963) expone un programa antipoético, no solo porque se devorara la tradición que conoce y la reescribe a su modo y, de acuerdo con sus intereses estético-políticos, como lo hiciera Borges en "El escritor argentino y la tradición"; sino también porque recurre a la ironía: "modelo de elección" (63), al humor: "Este es un modelo "sui generis"/de niños que juegan al pin pin/sarabín" (64) y el rescate de la oralidad popular: "la niña quiere que usted se quede,/no se me vaya, por favor" (64). A diferencia de Parra, Subercaseaux "baja a los poetas del Olimpo" para fundar una antitradición que incorpora la subjetividad queer, de modo que no solo polemiza con el canon poético, sino también con los contemporáneos de la Generación del 38, principalmente narradores, quienes describen a un proto hombre nuevo hipermasculino que lucha por sus ideales. Si antes la voz poética 
invitaba a un "amigo", un tú queer y cómplice, a abandonar y "temerle" a la tradición poética canónica; ahora, en cambio, le recuerda que más vale dejar los "versos [que] sobran" (65) para así cantar (poetizar) con confianza sobre hombres, pues estos en contraste con los versos, -señala con picardía-, no sobran: "canta confiado, sin mirarte por dentro,/que los versos sobran y los hombres, no" (65). En suma, el arte poética de Subercaseaux consiste en una invitación a sus "iguales" ("amigo[s]"), esto es, a los poetas homosexuales a que canten con confianza sobre los hombres y los deseos que estos les despiertan. Sin embargo, para cumplir con este cometido deben distanciarse de la tradición poética canónica, o bien, queerizarla.

\section{La "alitas rotas" polemizan con el proto "hombre nuevo" del Frente Popular: la polémica de las masculinidades}

En el número nueve de la revista propagandística Vida Sana se señala que "El deseo de ser un buen miembro de familia, un buen trabajador, un buen ciudadano, da a la vida un valor inapreciable" (Rosemblatt 192). La promoción de valores de masculinidad hegemónica ${ }^{5}$ sustentada, principalmente, en la figura del padre que procrea, provee y protege constituye la célula básica del proyecto de vida familiar articulado por el Frente Popular en Chile. La pedagogía familiar diseñada por los gobiernos frente populistas implicó establecer una normativa de los géneros, estableciendo roles para cada uno, a fin de contribuir a fortalecer la nación y sus rasgos identitarios: "Las reformas materiales y morales de las relaciones de género que emprendieron estaban estrechamente ligadas a su forma de hacer política, a su proyecto para reformar el Estado y a su definición de identidad nacional (Rosemblatt 183). El "buen miembro de familia", "buen trabajador", y por tanto, modelo de "buen ciudadano" viene a destacar la erección de una masculinidad que es a la vez la erección de un país potente que engendra nuevos hombres, y que como hemos señalado, ha sido productivizada por los ilustres "hijos del salitre" de la viril Generación del 38, quienes colaboran en "constitución colectiva de la masculinidad" (Conell 63).

\footnotetext{
${ }^{5}$ Entiendo "masculinidad hegemónica" a partir de Connell como "la configuración de la práctica de género que incorpora la respuesta aceptada, en un momento específico, al problema de la legitimidad del patriarcado, lo que garantiza (o se considera que garantiza) la posición dominante de los hombres y la subordinación de las mujeres" (117).
} 
Dossier. Ignacio Sánchez Osores. "Valparaíso, o la loca geografía del deseo: infancia queer y cruising homosexual en Quince Poemas Directos (1936) de Benjamín Subercaseaux".

Benjamín Subercaseaux, el poeta que invitaba a abandonar los versos, pero no así a los hombres en Quince poemas directos (1936) polemiza abiertamente con la configuración de masculinidad hegemónica promovida por el Frente Popular. La puesta en escena de un proto "hombre nuevo" que, luego la Unidad Popular asumirá como baluarte de la nación, será cuestionado por Subercaseaux y, más aún, propondrá un particular hombre nuevo: el queer. El poeta problematiza y propone una masculinidad divergente, exponiendo cómo las normas iterativas de la matriz heterosexual son impuestas desde la niñez ("El niño"), pasando por la adolescencia ("El adolescente") y hasta la adultez ("El hombre"). El poeta discute cómo es que el Estado encarna a una institución masculina, cuyas "prácticas de organización [...] se estructuran en relación al ámbito reproductivo" (Connell 111).

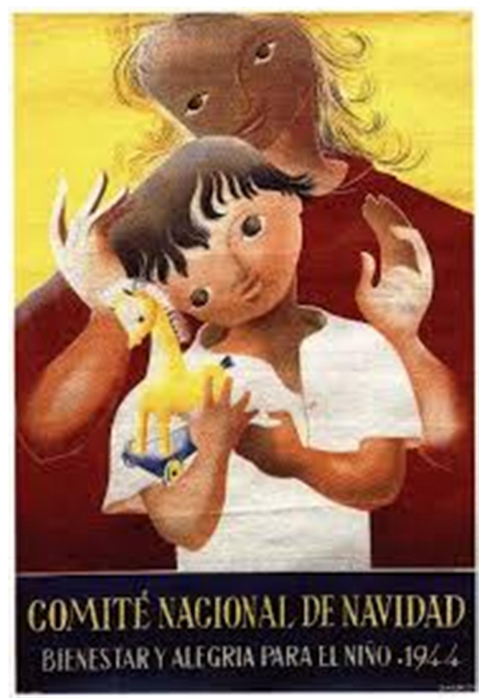

Figura 1. Comité Nacional de Navidad. Carlos Sagredo, 1944.

El afiche que vemos corresponde a la Comisión Nacional de Navidad de 1944, difundido tres años después de que el Frente Popular se ha disuelto. A pesar de que ha transcurrido un tiempo desde que oficialmente este conglomerado político dejó de erigirse como tal (1941), la imagen condensa visualmente la preocupación política que este tenía por la figura del niño. El sintagma "el niño" es revelador de la preparación y preocupación estatal de un niño en específico: aquel que representa el "futuro reproductivo" (Edelman 18). La ilustración muestra a un niño que mira fascinado y cándidamente un juguete, mientras que detrás de él se encuentra la figura de una mujer, que bien pudiera ser la madre; 
pilar fundamental de la economía doméstica del género femenino. Bajo esta imagen se inscribe el mensaje "Comité Nacional de Navidad". Bienestar y alegría para el niño" 1944, declaración clave que acentúa el énfasis en el cuidado de las políticas estatales por las infancias, que será retomado más tarde por el imaginario visual de la Unidad Popular en tanto vehículo de una "biopolítica afirmativa" (Ayala 137) ${ }^{6}$. La kinésica de las manos de la mujer devela una preocupación por la protección y cuidado del niño, un infante de mirada inocente que viste una camiseta blanca, color que simboliza su pureza y su disposición al docilizamiento al que es y será sometido. Asimismo, la inclinación del niño connota lo proclive que es al debilitamiento, de modo que ese doblez indica la posibilidad de desviarse de la pedagogía masculinista del Frente Popular y, a la vez, señala el rol de enderezamiento que le compete a la familia como célula básica del Estado. La historia de esta imagen nos remite a las representaciones visuales de la matrona, dado que en estas la Virgen María sostiene al niño Dios entre sus brazos, de manera análoga a cómo aparecen madre e hijo en el afiche.

El modelo de la política gubernamental al mismo tiempo que difunde la imagen de masculinidad viril, sana, y por tanto, alejada de los vicios, aboga, además -como vimos en el afiche- por la preocupación de las infancias, poniendo énfasis en el abandono y la ilegitimidad. En particular, y de acuerdo con Karim Rosemblatt, esta última se subsanaba entregando bonificaciones por cada hijo o hija que naciera dentro del matrimonio. Para el entonces Ministro de Salubridad del gobierno de Pedro Aguirre Cerda, Salvador Allende, tanto el abandono como la ilegitimidad eran las causantes de la morbilidad y mortalidad infantil, de modo que si estas se reducían "la acción concertada de padres y políticos aseguraría el progreso de la nación" (Rosemblatt 182). El énfasis puesto en la infancia despliega la politicidad del "futurismo reproductivo" (Edelman 18) ${ }^{7}$ que conduce al Estado a preocuparse por la salud y el bienestar de los niños y niñas, pues el futuro de la nación

\footnotetext{
${ }^{6}$ Matías Ayala advierte que "la figuración visual de los niños durante la Unidad Popular (1970-1973) fue también parte de la pugna política y biopolítica en torno a lo sensible y lo decible de esos años. Las fotografías, afiches, cubiertas de discos musicales, publicaciones y cómics que aquí se leen conforman un archivo visual heterodoxo en el cual la imagen de los niños aparece como una imagen prominente tanto del proyecto político como también del reordenamiento político que la Unidad Popular intentó llevar a cabo" (137)

${ }^{7}$ Lee Edelman señala que el futurismo reproductivo da cuenta de "términos que imponen un límite ideológico al discurso político como tal, preservando en este proceso el privilegio absoluto de la heteronormatividad al hacer impensable la posibilidad de una resistencia queer ante este principio organizador de las relaciones colectivas, dado que la deja fuera del terreno político" (18-19).
} 
Dossier. Ignacio Sánchez Osores. "Valparaíso, o la loca geografía del deseo: infancia queer y cruising homosexual en Quince Poemas Directos (1936) de Benjamín Subercaseaux”.

depende, finalmente, de ellos. El niño del Frente Popular no es otro que aquel que señala "una fijación fetichista de la heteronormatividad" (Edelman 44), de modo que el niño queer desaparece del mapa político estatal.

En el poema "El niño" Subercaseaux realiza una lectura crítica del proyecto de las infancias de Aguirre Cerda y Allende en tanto este plan no contempla la incorporación de todas las infancias, ya que hay unas que resultan problemáticas para la planificación biopolítica que tienen en marcha. En este se expresa cómo es leída la queeridad de un niño dentro del "proyecto de familia" promovido por el frente populista:

Aparece; criatura voraz, de inquietudes inmundas. Egoísta, fisiológico, repugnante.

La madre está feliz; el padre, avergonzado, torpemente satisfecho: ridículo, sobre todo (69)

La aparición del niño queer aparece ligada al exceso, y por tanto, como una figura que excede la (hetero) norma: "criatura voraz" y, simultáneamente, es vinculada a la inmoralidad, toda vez, que sus pensamientos, deseos, inquietudes son inmundos. La inmundicia del niño queer ensucia la nación que el proyecto estatal desea sana, robusta y limpia y, por consiguiente, se erige como un "egoísta" que complica su reproducción. Las infancias queer derivarán en sujetos que al no transformarse en potenciales padres se convierten en subjetividades carentes de compromiso con el proyecto nacional, y en efecto, no son más que fisiologías, esto es, solo cuerpos improductivos que no trabajarán en aras de su fortalecimiento. En este sentido, podemos afirmar que Subercaseaux entiende lo queer de estos niños, tal como la comprende Lee Edelman, o sea, como una contrarrespuesta a la heteronormatividad impuesta que viene a "significar la barra sobre cualquier realización de la futuridad; la resistencia, interna a lo social, a toda estructura o forma social" (21).

Sin embargo, esta contrarrespuesta se actualiza una vez que se han determinado las líneas de fuerza que ejercen la coerción de las subjetividades en formación. De ahí, que la voz poética exponga cómo se pone en marcha el dispositivo de la homofobia al caracterizar al niño queer como "repugnante". Subercaseaux parece decirnos que en los anales nacionales las infancias queer más que aparecer, desaparecen. La queeridad del niño lo sitúa en el espacio de la abyección y suscita en el padre vergüenza, mientras que la madre edípica se siente feliz. La vergüenza paterna es motivada por su fracaso en la construcción 
de una familia que no cumple con las expectativas del "buen miembro" de la familia nacional. La voz poética, singulariza al padre como un sujeto "ridículo, por sobre todo" (69), pues se avergüenza de su hijo. Es más, el poeta cuestiona la crianza de los padres, quienes patologizan al niño queer: "Los padres van y vienen con entera libertad, "como si/ el hijo hubiera nacido ciego o imbécil” (70). La infancia queer es descrita como una etapa paradójica que tiene mucho de clarividencia y de lobreguez, de modo que la aproxima a un estado agónico con todo el carácter de aflicción que comporta para los niños y niñas enfrentarse a los dictámenes genéricos. El dispositivo de heterosexualización que se impone a los niños devela la absurdidad que en estos contextos tienen las prescripciones genéricas en la infancia y, asimismo, expone el carácter performativo de las normas de género que se le asignan al nacer a los niños, las cuales no son más que "Juegos mecánicos. Mecánica del juego. Siempre el ataúd/vecino de la cuna" (69). La contigüidad entre ataúd y cuna connotan los "sueños de exterminio" (Giorgi 16) que recaerán más tarde sobre estos pequeños seres cuando crezcan, y al mismo tiempo, señala el actuar de lo que Paul B. Preciado denomina "policía de género", es decir, un dispositivo biopolítico que "vigila las cunas para transformar todos los cuerpos en niños heterosexuales. O eres heterosexual o lo que te espera es la muerte" (64). El poema se encarga de describir la hiperfascinación del adulto sobre las infancias, advirtiendo como esta preocupación esconde tras de sí una maquinaria ideológica que se encarga de disciplinar cuerpos que aún están en (de) formación. O mejor dicho, la pedagogía familiar expone sus miedos, represiones y fantasías disfrazados de un gesto proteccionista.

En definitiva, Subercaseaux en este poema revela la invisibilización de las infancias queer y el sufrimiento que caracteriza estas: "Dolor, dolor. Cada soplo es una herida" (69) por no encajar en el ideal de proto "hombre nuevo" que la comunidad imaginada había deparado para ellas. El poeta retrata con sensibilidad y ternura el sufrimiento y el padecimiento de los "niños de lluvia": "La lluvia gime en los vidrios" (70) y antes que ofrecer una mirada recriminadora, los acoge e invita a no abandonar sus deseos: "Niño: colecciona tus placeres; amontónalos en tus pe-/queñas manos" (69). El imperativo de

\footnotetext{
${ }^{8}$ Niño de lluvia es el nombre de una novela autobiográfica de Benjamín Subercaseaux. Según, Lorena Amaro, "Daniel es, en suma, lo que el novelista denominará a lo largo de todo su relato, un "niño de lluvia", categoría que define en su oposición a la de los "niños de sol”, que parece encarnar la masculinidad hegemónica de principios del siglo XX en América Latina” (227).
} 
Dossier. Ignacio Sánchez Osores. "Valparaíso, o la loca geografía del deseo: infancia queer y cruising homosexual en Quince Poemas Directos (1936) de Benjamín Subercaseaux”.

"hacerse hombre" es polemizado por Subercaseaux y con ello, toda la construcción sobre masculinidades hegemónicas promovidas por el Frente Popular al desmontar el carácter performativo y ficcional del género: “¿¿Ha nacido un hombre?/-No, un ser./Pero hay algo que acaba de morir" (70). Subercaseaux polemiza con el imperativo genérico que se les impone a los niños y niñas al nacer, aquel que Butler nos recuerda no olvidar:

En el caso del género, debemos tener en cuenta que generalmente son los médicos quienes declaran que un recién nacido es un varón o una hembra, y en el caso de que su enunciado no fuera audible, la casilla que marcan en los documentos legales que han de enviarse al registro no deja lugar a dudas (35).

El poeta tiene plena conciencia de que la infancia es una etapa formadora ${ }^{9}$ más que reformadora, por ende, categorías binarias como "hombre" y "mujer" resultan inapropiadas para aproximarse a las infancias queer y terminan por sepultar ("hay algo que acaba de morir") la indefinición que las caracteriza, o en palabras de Pedro Lemebel, impedir que las "alitas rotas" vuelen (35). El niño de Subercaseaux polemiza con el "Niño figural [que] encarna por sí solo el ciudadano como ideal [...]" (Edelman 31) y que se erige, por consiguiente, como la figura modélica que el Frente Popular se propuso instituir.

Si en el poema "El niño" se exponía el (des)aparecer de las infancias queer, en "El adolescente" se declara el lugar marginal que este ocupa en la literatura: "[...] esta vez al margen de toda literatura" (73). La (des)aparición, la marginalidad y presencia de las infancias y adolescencias queer en el plano literario será tematizado con insistencia en las poéticas de los novísimos Diego Ramírez (El baile de los niños) y Gustavo Barrera Calderón (Cuerpo perforado es una casa). Sin embargo, Subercaseaux ya en los años 30' problematizará su invisibilización señalando su disputa representativa, los dispositivos homofóbicos y heterosexualidazores a los que estas se ven enfrentadas, pero también el derecho de los niños y adolescentes a descubrirse y desear.

El "niño de lluvia" en este poema ha crecido: "Brazos demasiado largos; mangas demasiada cortas" (73) y es descrito por la voz poética como “Ángel y bestia” (73),

\footnotetext{
${ }^{9}$ De acuerdo con el teórico Jack Halberstam, "La inestabilidad de la infancia significa que el género es necesariamente algo incierto antes de que las dinámicas familiares heteronormativas lo conviertan en algo claro y "verdadero". La criatura, por ende, puede ser un vehículo tanto de las fantasías sociales más normativas como de los miedos sociales más extravagantes" (80).
} 
connotando la dualidad entre la inocencia que aún cabe en las mangas de la infancia y el pecado del adolescente queer, quien comienza a aventurarse en el descubrimiento de los placeres y deseos:

Carreras inexplicables; pudores feroces; palabras groseras, sabores hipotéticos de la carne, gustados en la soledad de los campos, de las playas lejanas y de las piezas sin sol.

Un imposible en su corazón. ¿Vergüenza? ¿Qué otra cosa podría sentir ante la brutalidad del amor? (73).

La descripción del cuerpo adolescente queer como una "divinidad, ideal palpitante del ser pagano" (73) vincula a Subercaseaux con autores queer como Alberto Nin Frías y Porfirio Barba-Jacob quienes realizan un culto a las figuras del efebo y del adolescente desde una mirada idealizante. La voz poética expresa que este joven ha experimentado los placeres proscritos de la carne ("sabores hipotéticos de la carne") a escondidas ("gustados en soledad") del ojo censor de la sociedad homofóbica quien lo obliga a sentir vergüenza por sus deseos desviados. En efecto, el amor homosexual se sitúa como una "ficción normativa" que en su imposibilidad se animaliza ("brutalidad del amor"). No obstante, el poeta expresa la libertad y el derecho que el adolescente queer tiene para disfrutar de "tardes endemoniadas" (74) que lo dejan exhausto y débil: "a pesar del cansancio de la mirada y la debilidad del cuerpo" (74). El poema, al igual que el anterior, finaliza con un cuestionamiento del binarismo de género impuesto a los adolescentes, quienes aún se están descubriendo y experimentando sus cuerpos y afectos: ¿Ha nacido un hombre?/No: la ternura. Pero hay algo que comienza a sufrir" (74). Las infancias y adolescencias para Subercaseaux no pueden ser definidas a partir de una matriz genérica excluyente que separa entre hombres y mujeres, antes bien, las entiende más allá de la diferencia sexualanatómica y se enfoca en los afectos, la diversidad y la indeterminación, orden de valores que el proyecto de familia del Frente Popular no acoge.

Por último, en el poema "El hombre" se expone el fracaso del proyecto del proto "hombre nuevo" en tanto sostén de la familia nacional. El niño y el adolescente queer no acudieron al imperativo de "hacerse hombre", y por tanto, no se sumaron al robustecimiento del cuerpo patrio ni a las marchas reivindicativas de la anatomía de la lucha. De hecho, el trabajo para este hombre no constituye un motor y agente de cambios; 
Dossier. Ignacio Sánchez Osores. "Valparaíso, o la loca geografía del deseo: infancia queer y cruising homosexual en Quince Poemas Directos (1936) de Benjamín Subercaseaux".

es más bien un medio de subsistencia que ni siquiera le permite acceder a lo que desea: “El trabajo?/ Un medio para adquirir lo que ya no desea” (77). El "hombre nuevo” queer no lucha con otros ni en contra de otros, dentro del marco político frente populista, sino con la sociedad homofóbica, "luchas exteriores" (77) pues esta lo convierte en una subjetividad extranjera que no reconoce sus propios deseos ni su entorno:

Pero llega un día, desde más lejos que la vida, en que ya le es imposible reconocer su corazón, su ciudad, su calle.

El mundo le parece absurdo, porque hay alguien sobre la tierra que es su calle, su ciudad, su corazón: un mundo desconocido (78).

La sociedad y la promoción del imperativo heterosexual conduce al extrañamiento de la subjetividad poética, para quien el mundo "le parece absurdo", pues todo lo que supuestamente le pertenecía, ha devenido en un "mundo desconocido" del que no forma parte. La extranjeridad se le concede por no asumir el rol de "hombre nuevo", es decir, por traicionar el ideario de familia nacional sana y trabajadora. De ahí, que la voz poética, a través de una pregunta retórica, polemice con el mandato de masculinidad hegemónica promocionado por el Frente Popular: “ $¡ A h$ ! hombre, hombre. ¿Quién te ha dado el derecho de llamarte así? (78). Más adelante responde a la pregunta de rigor: “¿Ha nacido un hombre?/Sí. Pero hay algo que no logra vivir" (78). El adversativo señala la disonancia del nacimiento de este hombre. Sí es hombre, pero uno queer y aquello que precisamente no logra vivir es la hegemonía del proto "hombre nuevo" heterosexual. La queeridad del hombre poetizado por Subercaseaux ofrece un campo político de resistencia al proyecto estatal, una enunciación que discute los ordenamientos ideológicos que en su exceso en la preocupación del "Niño figural", como nos diría Lee Edelman, deja al descubierto las exclusiones de los niños y niñas "reales".

En esta tríada de poemas Benjamín Subercaseaux relata el desacomodo de la infancia, adolescencia y adultez de un "hombre nuevo" queer que no se alista a las filas con los "hijos del salitre", sino que vive su homosexualidad como un extranjero desde que es niño. Dicho de otra manera, Subercaseaux señala que cuando el niño queer "se sale de la cadena de montaje de la producción heterosexual [...] se dirige hacia un nuevo proyecto" (Halberstam 83). El poeta expone la insistencia de imperativo heterosexual en cada uno de 
los poemas mediante la pregunta ¿Es un hombre?, interrogante que sería asumida por el proyecto de la política frente populista, es decir, aquella que requería del "buen miembro de familia", "buen trabajador" y "buen ciudadano". El hombre nuevo queer poetizado por Subercaseaux desarticula la normativización de las construcciones de masculinidad hegemónicas y propone una masculinidad divergente que hace tambalear la pedagogía familiar, de modo que queda claro que la narrativa del "futurismo reproductivo" (Edelman 18) se alía con los relatos articulados por la anatomía de la lucha, mientras que la narrativa de la subjetividad queer se alía con relatos de la anatomía del deseo, los cuales vienen a interrumpir o desviar el imaginario construido en torno al ser hombre.

\section{La penetración del cuerpo masculino en el puerto de Valparaíso: cruising y homoerotismo...}

La propuesta poética de Benjamín Subercaseaux consiste en edificar una ciudad queer que se construye a partir de cuadros o escenas, típicamente, asociables a la poesía posmodernista de Carlos Pezoa Véliz. No obstante, los cuadros de este “Álbum porteño queer" están trazado mediante significantes que, más que describir la ciudad en términos femeninos, se prefiere homoerotizarla. Esta queerización de la ciudad aparecerá en el proyecto ensayístico Chile o una loca geografia (1940), ya que en este se configura una topografía de la identidad nacional, pero simultáneamente y de manera solapada, también se configura una topografía del deseo homosexual. De acuerdo con Cristián Foerster, la "predilección por los cuerpos musculosos y bien delineados no solo se liga a su homosexualidad, sino también a una concepción viril de la vida" (57). Concuerdo con el investigador, pero creo que la descripción de una "raza" o comunidad imaginada viril es solo una excusa para construir una topografía del deseo homosexual exquisita en detalles de la anatomía masculina. El ensayista incorpora una mirada queer sobre el relato nacional que viene a constituir una especie de contrarrelato en el que se da cabida a los deseos proscritos de las subjetividades homosexuales:

Por el sexo se pavonean los cargadores de la Vega, medio desnudos, haciendo alarde de su musculatura vibrante bajo la carga enorme o la "cuna" repleta de frutas. Jamás veremos una estatura descollante y 
Dossier. Ignacio Sánchez Osores. "Valparaíso, o la loca geografía del deseo: infancia queer y cruising homosexual en Quince Poemas Directos (1936) de Benjamín Subercaseaux".

apuesta, aunque haya también hombres mal hechos, pero fuertes, que podrían hacerlo igual (105).

Si en el proyecto estético-político, fundamentalmente, heterosexual de los escritores de la Generación del 38 estos cuerpos "no cabían en la lengua” (Opazo 15), en cambio, en el proyecto estético-político de Benjamín Subercaseaux estos tienen la obligación de aparecer porque su obliteración implica una mirada traicionada que pintaría "cuadros sin filiación" (123). Por el contrario, la mirada del escritor será integradora y tendrá un carácter reformador, toda vez que viene a desestabilizar los relatos de géneros existentes. Él pinta “cuadros [con] filiación" generados a partir de una mirada gozosa de cuerpos masculinos que rebosan la gramática prescriptiva de la lengua hegemónica, pues eliminarlos sería no asumir sus deseos, y por tanto, implicaría un síntoma de la represión: "Eliminar el sexo de lo pintoresco santiaguino sería describir una serie de cuadros sin filiación alguna. Sobre todo que un hombre sin malicia podría estar diez años y más mirando estas cosas-como lo estuve yo- sin percatarse de nada" (123). La ironía del mirar sin percatarse de nada de un "hombre sin malicia" constituye una declaración torcida sobre su proyecto estético porque, precisamente en este, se halla una sobreexposición de cuerpos masculinos y una respectiva mirada queer sobre ellos.

En Quince poemas directos (1936) la sobreexposición de los cuerpos masculinos es elocuente, de modo que mirada del flâneur se desplaza para darle lugar a lo que denomino como cruisser, figura que parafraseando a Edgar Allan Poe, no es otro que aquel hombre que penetra a la mutitud marica o que es penetrado por esta. Se encuentra a medio camino entre el flâneur baudeleriano descrito por Walter Benjamin y el poseur decimonónico teorizado por Sylvia Molloy. Se integra junto ambas figuraciones en tanto todas habitan gozosamente la ciudad moderna y asisten al despliegue de su botánica [de] asfalto" (Benjamin 50) para asumir su única empresa: el ocio y la improductividad. El cruisser comparte con ambos sujetos una pulsión escópica: por un lado, Benjamin nos dice que "el encanto del habitante urbano es un amor no tanto a primera vista como a última vista" (601) y por otro, Molloy enmarcará al poseur como agente y desencadenante predilecto de la exhibición como género y forma cultural del siglo XIX (43). Sin embargo, la figura de Subercaseaux va más allá de la persecución de la mirada que anima el deseo exhibicionista; pues esta constituye solo un estímulo que culminará en una epistemología del contacto 
cuerpo a cuerpo o, mejor dicho, de una epistemología háptica. Si el Víctor Hugo que Baudelaire admira es aquel en cuyas letras "la multitud penetra con la poesía como objeto de contemplación" (Benjamin 77); el cruisser, en cambio, se solaza en la activación de una poética táctil que desplaza la pulsión escópica como matriz articuladora de un nuevo sensorium. Si "el flâneur nocturno recorre una ciudad literalmente luminosa" (Monteleone 25); el cruisser, en cambio, merodea la ciudad oscura, aquella que escapa al ojo censor y que abre un abanico de posibilidades sexuales.

Dado lo anterior, entiendo por cruisser a una figura errática en su doble acepción: como subjetividad torcida o defectuosa y como subjetividad deambulante o callejera que se mueve en el reino de la posibilidad al ritmo de la urgencia y fisurando la normatividad de régimen diurno. En su andar y su trayecto nomádico por los avatares nocturnos homocorporaliza la ciudad, la diseña, la arquitectura y, simultáneamente, la habita; y es que como expresa Néstor Perlongher: "vivir la ciudad es sentirla, y en ese sentimiento inventarla. No es una invención individual subjetiva, sino colectiva "impersonal" y se transmite a la manera de un contagio entre cuerpos en contorsión tremolante" (144). La ciudad homoerotizada se erige, por tanto, en espectáculo de tramas deseantes, de modo que plazas, parques y calles oscuras devienen escenarios de verdaderos tableaux vivants a la luz de las candilejas y faroles.

El transitar despreocupado, la mirada segmentada dirigida hacia los cuerpos masculinos, las trayectorias en direcciones oblicuas distancia al cruisser del flâneur, dado que este último es quien permite la asunción de una "literatura panorámica" (Benjamin 49) orientada a la totalidad y la extensión. El cruisser, en cambio, al desplazarse del terreno de lo visual a lo háptico y al servirse solo de cuerpos fragmentarios, de contactos urgentes y de capturas fugaces inventa una literatura ya no extensiva, sino intensiva, generadora de un un particular sensorium cómplice.

El cruisser de Subercaseaux es caracterizado en "Valparaíso", el texto que abre el poemario, como un "Andante apasionato a la manera antigua" (15). Este "andante apasionato", en la estrofa titulada "Paisaje", del poema "Apuntes diurnos" enuncia la presencia de dos paisajes que recortan su mirada sobre la ciudad porteña:

Contra el mar, una vieja grúa corta en dos el paisaje de mi ventana: chimenea de cocina y calaminas grises, ca- 
Dossier. Ignacio Sánchez Osores. "Valparaíso, o la loca geografía del deseo: infancia queer y cruising homosexual en Quince Poemas Directos (1936) de Benjamín Subercaseaux".

laminas rojas, calaminas verdes. En un ángulo: SE VEND-

DE.- ERRAZURIZ 1914...

Hay algo más, pero el humo del tren me impide verlo (26).

Esta aparente y sin importancia descripción de un cuadro de Valparaíso viene a constituir una operación metaliteraria que plantea la existencia de dos paisajes: el primero, es aquel que se deja ver claramente y que tiene carácter mimético, es decir, cuyos referentes deben ser leídos/vistos de manera unívoca: “chimenea de cocina y calaminas grises, ca/laminas rojas [...]" (26). Mientras que el segundo es aquel que se escabulle y que dificulta su observación. En este contexto, propongo que este último constituye un paisaje queer, toda vez que nos remitimos a la categoría de paisaje como reconocimiento (Roger). En este caso el paisaje es queer porque implica una particular y desviada forma de mirar, o mejor dicho, el paisaje portuario es queerizado por Subercaseaux, toda vez que su mirada se desvía para desautomatizar los significantes con los que habitualmente se ha descrito la ciudad en la poesía chilena (Rubén Darío, Carlos Pezoa Véliz). En el puerto no solo penetra el cuerpo homosexual, sino que este mismo espacio es también penetrado en tanto es alegorizado como un cuerpo masculino.

El poeta describe entre líneas una escena sexual que acaece en y con el puerto: "Cuando se te vayan adentro/con mucho de rancha en el alma" (17); "Desde Drake y Cavendish/te riega la savia marina" (15); "se adentró en tus carnes/la savia ardiente del extranjero" (18). El sintagma "cuando se te vayan adentro" y el significante "savia marina" y "savia ardiente" -en el contexto del poema- connotan una eyaculación, luego del ajetreo de la actividad sexual: “¡Arrástrate por las aduanas/en piruetas deliciosas” (16). El paisaje queer pintado por Subercaseaux activa otro de régimen de mirada que permite mirarlo/leerlo como una especie de desnudo artístico, puesto que el puerto es exhibido como un cuerpo sexualizado: "tú que expones tu cuerpo abierto/ con tal sinceridad/ que los hombres te reconocen/llamándote simplemente "el puerto"” (17). El cuerpo del puerto que, alegoriza un cuerpo masculino, seduce a los hombres, quienes se aproximan a este para abrazarlo; de tal manera que la pretendida masculinidad de estos últimos es devaluada: son "vírgenes asustadas", dado que en la construcción oposicional-binaria de los géneros, expresar afectos es propiamente una acción femenina: 


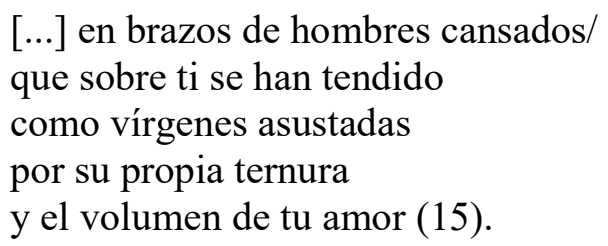

Si atendemos a una lectura metonímica de este paisaje, el cuerpo homoerótico del puerto es, además, una extensión de la subjetividad queer que lo "penetra":

Estás henchida de destreza que se cuela en tus muchachos/a lo largo de los muelles como una difícil maniobra en lo alto de una cofa (16).

La destreza de las antes mentadas "piruetas deliciosas" (16) del puerto se extienden y se "cuela[n]" (16) a los muchachos, quienes "como una difícil maniobra" (16), penetran un cuerpo. El significante "cofa", perteneciente al léxico marino y que refiere a una meseta utilizada para "facilitar la maniobra de las velas altas" (DRAE), constituye una metáfora que viene a significar un encuentro sexual homoerótico, debido a la forma fálica de las velas. La elección de pintar un paisaje queer del puerto sitúa a Subercaseaux en la tradición de escritores y artistas quienes han tematizado la homosexualidad vinculada al imaginario marino.

El cruisser de Quince poemas (1936) recorre la ciudad portuaria reconociendo y advirtiendo el nuevo sensorium de modernidad, que cual prisma, activa múltiples miradas. Con todo, el cruisser deambula por los vericuetos de la urbe con un ojo voyeur enfocando su mirada en anatomías masculinas:
"Embarcadero"
Miran arriba los boteros desde sus botes.
Miran abajo los ociosos desde las gradas.
Yo miro a los ociosos y a los boteros
y la brisa inventa espumas, gaviotas y banderas (26).

El cruisser inventado por Subercaseaux desvía su mirada para dirigirla a fragmentos de anatomías masculinas y ha entrenado un ojo voyeur que le permite rápidamente encuadrar y sucumbir a sus deseos homoeróticos: "Por las callejuelas que suben, la curva 
Dossier. Ignacio Sánchez Osores. "Valparaíso, o la loca geografía del deseo: infancia queer y cruising homosexual en Quince Poemas Directos (1936) de Benjamín Subercaseaux".

del muslo trepida gloriosa" (25). El significante muslo que podría hacernos pensar que corresponde a una mujer no parece tener asidero, pues en el poema "Pureza" aparece para describir un retrato de un jovencito que deambula por las noches porteñas:

En ti, creatura, se saciaron

los eternos símbolos de la Creación:

No faltó la piel suave ni el ojo brillante, ni la soltura del torso recargado de atractivos inconscientes que se escapan sin pagar.

Y en torno, los deseos, abrumados de sueño, empecinados, como yeso embrutecido de salvajes escultores que moldean hasta las miradas tristes de tu carne ardiente.

Y te vas por las noches del mundo, con mucho sollozo contenido en el muslo, $\mathrm{y}$ un deseo infinito de tu renuncia en el alba del cuerpo (39-40).

Este poema-retrato tiene su antecedente en "Retrato de un jovencito" de 1911 escrito por el poeta colombiano Porfirio Barba-Jacob: "Pintad un hombre joven, con palabras leales $[. .$.$] / Que haga temblar las carnes un ansia contenida; que el torso y la frente,$ y los brazos nervudos [...]" (101). Subercaseux innova no solo porque el retrato elaborado es más audaz en términos de significantes, sino porque también corresponde a la figura de un joven mostacero porteño que es descrito como un sujeto dotado de perfección física: "En ti, creatura, se saciaron/los eternos símbolos de la Creación" (39); de modo que este poema se integra a la tradición de escrituras homosexuales que citan la cultura helénica para expresar sus deseos homoeróticos.

La voz poética expone las dinámicas de la prostitución masculina o, más bien, se centra en las transacciones sexuales fallidas y en las consecuencias que tienen estas para sus ejecutores. La anécdota del poema señala cómo al joven mostacero, a pesar de que nunca le faltan clientes está, sin embargo, expuesto a ser engañado, pues no siempre le pagan sus servicios. La metonimia "torso" alude al cuerpo del cliente, quien aun "recargado de atractivos inconscientes [...] se escap[ó] sin pagar" (39). La aparente huida del sujeto que 
no cumplió el contrato sexual compadece al yo lírico, quien describe el fracaso del trabajo nocturno: "Y te vas por la noche del mundo,/ con mucho sollozo en el muslo,/mucho cansancio en tus brazos fuertes [...]" (40). El "sollozo en el muslo" no solo es indicativo de los riesgos de no obtener paga, sino que también da cuenta de la estrecha relación entre deseo y violencia: "empecinados, como yeso embrutecido/ de salvajes escultores que moldean/hasta las miradas tristes de tu carne ardiente" (40). Dado lo anterior, y en contraste con la realidad del joven, la voz poética señala la fuga, a partir del deseo de una renuncia, que se advierte (im)posible: "y un deseo infinito de tu renuncia/en el alba del cuerpo" (40). Subercaseaux en este poema expone la condición marginal de una subjetividad que aparecerá con más preeminencia en la narrativa de medio siglo con Luis Rivano y Alfredo Gómez Morel y, posteriormente, en los noventa y dos mil en las crónicas de Pedro Lemebel.

En Quince poemas directos (1936) se configura una "loca geografía” del deseo en la que Subercaseaux elabora su propio "Álbum porteño queer". En este caben no solo los cuadros paisajísticos de una ciudad descrita en términos alegóricos como una anatomía masculina, sino también se señalan las rutas de una cartografía homodeseante y las subjetividades que trazan los desvíos de la heteronormatividad. El cruisser inventado por el poeta ocupa un lugar central en el proyecto poético y, por consiguiente, sus andanzas, recorridos y la disposición de su ojo voyeur vienen a instalar un ars amatoria de las prácticas sexo disidentes posibles gracias a la auspiciosa modernidad periférica de la ciudad portuaria.

En este ars amatoria Subercaseaux advierte, tal como señalaba al comienzo de este capítulo Alejandro Jodorowsky, que es el sujeto burgués- homosexual la figura predilecta que baja a Valparaíso en busca de encuentros sexuales con el pueblo. En el poema “Apuntes diurnos" el yo lírico le recomienda no desviar su itinerario porque quizá podría ingresar a la cartografía deseante de los varones proletarios que deambulan por la ciudad nocturna:

"A un hombre serio

Correctamente, burguesamente, te paseas por Pedro Montt. No retrocedas mucho: llegarías al Viejo Puerto. No vayas muy lejos: caerías en el Barón (25). 
La homofonía del significante "Barón", correspondiente al nombre de uno de los cerros emblemáticos de la ciudad de Valparaíso, le sirve al poeta para prevenir a los "serios hombres burgueses" de caer en los brazos de un "varón". El ars amatoria es conocida y ha sido experimentada por la voz poética, por eso, más que un consejo verdadero constituye una ironía, el tropo más queer (46), según Lee Edelman, pues precisamente lo que hace esta es torcer los sentidos de una expresión. En este fragmento la negación: "no vayas muy lejos", finalmente, encarna una afirmación. La negación que afirma no es sino otra cosa que una invitación a perderse por los vericuetos de la seductora cartografía homodeseante, por tanto, en términos discursivos es una oración desiderativa.

El itinerario de esta "loca geografía del deseo" comienza a trazarse una vez que el cruisser decide ir lejos para sucumbir a la anatomía del varón, pues ante todo "Él amaba la vida" ("Éll" 51). La pulsión deseante de la subjetividad poética que busca perderse entre y con el pueblo porteño contrasta con la prescripción del ocultamiento:

En el fondo, una misma historia lamentable que no sabemos nunca, pero que sospechamos siempre.

Digámosela al oído y veremos que les sorprenderá, como sólo puede sorprender un secreto muy oculto ("V" 36 ).

La "retórica del secreto" (Balderston 23) persigue ocultar el secreto a voces "que sospechamos siempre" (36), pero que las apariencias resguardan cínicamente para evitar el desprestigio del proyecto familiar de la nación, impulsado por el Frente Popular, el que aunque liberal en sus declaraciones deja ver el conservadurismo político-moral en lo que respecta a las políticas de la sexualidad. La Belleza entendida como un bien debe, de acuerdo con las prescripciones heterosexualizadoras, mantenerse bajo discreción: "el ropaje de su discreción indispensable" (36). El secreto de la familia nacional debe "guardarse" como el ropaje y garantizar su lugar en el clóset, pues la "historia lamentable" aunque podría contar[se] si tuviera[n] más valor" (36) no se dice para no desestabilizar sus cimientos. Pese a anterior, la noche se convierte en una aliada para el sujeto homosexual, quien "Confiadamente,/ más allá de la Política, la Moral/ y sus necesidades", "[y porque] Él 
amaba la vida" (“Él” 51) se interna y penetra por la ciudad, despojándose de la pose simulada del "serio hombre burgués" que debe ocultar:
Y detrás de cada andar, felino, balanceado o aplastante, una historia propia de muy diverso interés, poblada de circunstancias secundarias que se escurren como aceite ("V" 36).

La rectitud de la pose de "hombre serio" y, asimismo, la rectitud del camino desaparecen momentáneamente -"se escurren como aceite" (36)- para poner en escena la pose de un cruisser quien tras la seducción de su andar carga con una historia personal de normalización de su sexualidad, que la política del Frente Popular con la promoción del "padre de familia" y la moral castigadora y culposa de la religión se encargan de defender. En cambio, la subjetividad poética opta por oponerse a estas prescripciones genéricas dirigiendo su mirada: "Él miraba, miraba" (“Él” 52) en los cuerpos masculinos que puebla la noche:

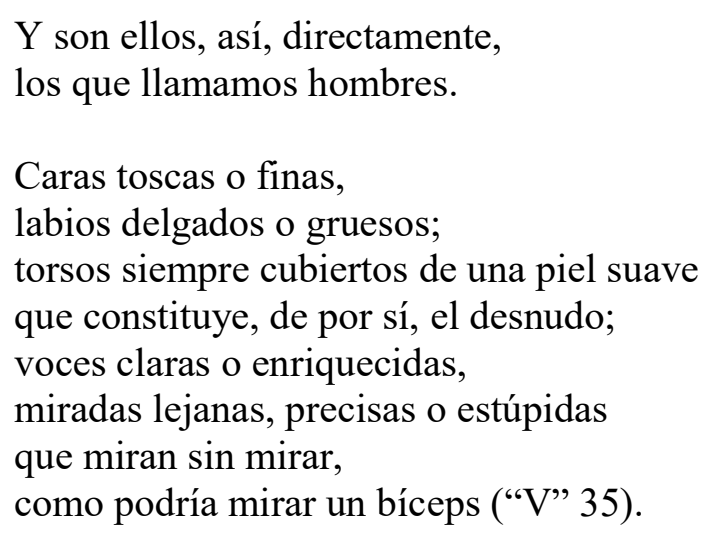

Subercaseaux en este poema pone en marcha la anatomía del deseo, y por supuesto en dirección contraria, a la viril marcha de la anatomía de la lucha, promovida por el Frente Popular y la Generación literaria del 38, que sus compañeros de "filas", asumieron y plasmaron literariamente. El poeta despojado de la "belleza" y sus ropajes retóricos desnuda la subjetividad homosexual a partir de una descripción fragmentaria del cuerpo masculino. La estrategia textual de esta anatomía del deseo se articula a través de oposiciones binarias de variables como la clase y la raza (caras toscas-caras finas; labios delgados- labios gruesos), y estereotípicamente, mediante dos tipologías de la 
Dossier. Ignacio Sánchez Osores. "Valparaíso, o la loca geografía del deseo: infancia queer y cruising homosexual en Quince Poemas Directos (1936) de Benjamín Subercaseaux".

homosexualidad, que años más tarde escritores como Néstor Perlongher y Pedro Lemebel indicarán: la loca (hiperfemenina) con sus "voces claras" (35) y el macho (hipermasculino) con sus "[voces] enronquecidas" (35). El "miran sin mirar"/ como podría mirar un bíceps" (35) revela una operación retórica que puede ser entendida en términos metaliterarios: estamos frente a una mirada escamoteada, huidiza, en definitiva, la del ojo voyeur del cruisser a nivel enunciado, pero también la mirada osada de la enunciación de la voz poética.

El cruisser no se encuentra solamente con subjetividades masculinas (obrero, mostacero, burgués serio), sino que también con subjetividades que vienen a complicar la idea misma de masculinidad, y por supuesto, el binarismo de género. En el poema "Ella" se representa una "nueva Victoria de Samotracia" (48): la travesti. El poeta construye una subjetividad travestida mediante una citación a la cultura helénica que lo autoriza para poetizar los desvíos del género y su carácter ilusorio. La elección de la escultura griega no solo es una estrategia retórica insertada en la tradición de escrituras homosexuales, sino que además es elegida porque la Victoria de Samotracia se encuentra ubicada sobre la proa de un barco. Dado lo anterior, Subercaseaux realiza una operación de traducción y recontextualización de esta figura en Valparaíso. Sobre barcos descansan los cuerpos de hombres y travestis que el ojo voyeur captura para ser poetizados y gozados.

Como sabemos, la Victoria de Samotracia es la escultura griega de una mujer sin cabeza, de cuyas espaldas se desprenden alas y es quien encarna a la diosa de la victoria llamada Niké. El lugar en el que se encuentra situada (sobre una proa) connota la entrada triunfal de las naves victoriosas. En el contexto del poemario, la Victoria de Samotracia porteña, en una primera lectura, alude a la entrada "victoriosa" de la figura travesti en la poesía chilena. Y en una segunda lectura, remite a una escena sexual travesti, toda vez que la proa del barco constituye un tropo visual fálico, solo posible de ser interpretado así, pues -como hemos visto -el léxico marino es resemantizado por el poeta desde una mirada queer.

La travesti porteña poetizada por Subercaseaux es una "mujer [para la que] se conjugaron las savias ornamentales, como decía Querubín" (47). La cita de Iluminaciones de Arthur Rimbaud ("savias ornamentales") le permite al poeta no solo instalarse en una genealogía queer, sino que lo faculta para destacar el carácter artificial de la figura del travesti: las "savias ornamentales". La "simulación" (Sarduy) del travesti a través de la 
indumentaria, el vestuario y los ornamentos constituye un ejercicio necesario para aproximarse a la imagen esencialista de toda mujer: "Sabía el precio de la belleza esencial /gustada a la sombra de las peores renuncias" (47). El carácter travestido o transgenerizado del travesti encarna la desestabilización de la normativa genérica, pues en esta figura concurre lo femenino, pero también lo masculino:

Ella, nueva Victoria de Samotracia despojada de sus velos por el viento de la orgía, de pie, entre los Propileos de sus muslos firmes, en la abundancia excesiva de recompensas que le pulían hasta la última arista de su pasión (48).

El sintagma "entre los Propileos de sus muslos firmes" (48) adquiere en el poemario una connotación masculina no solo porque el significante "muslo" aparece con insistencia cuando se describen cuerpos de hombres, sino porque en este caso aparece determinado por dos significantes que están asociados semánticamente a lo masculino: los muslos son "firmes" y en estos hay "Propileos", es decir, las piernas se describen como las entradas monumentales con columnas, propias de la arquitectura griega. Las columnas de los Propileos no sirven solo para metaforizar la delgadez de las piernas, sino más también para resaltar su firmeza. La Victoria de Samotracia porteña, de manera análoga al mostacero retratado en el poema "Pureza" es pulida, o sea, se encuentra participando de una escena sexual: "le pulían hasta la última arista de su pasión" (48). El deseo propio es el motor que la impulsa a arrastrase por las calles y aceras de la ciudad:

La desearan o no, ella lo quiso; entonces, como un grito apremiante de alarma la invadió la sirena del deseo por las piernas, el vientre, la mirada, y, temblando, se dejó arrastrar por las aceras, los muelles, las viejas tinas de baño esmaltadas de jabón y de lujuria (48).

En el poema se enuncia la práctica de simulación del travesti, sus deseos y encuentros sexuales hoteleros; y, simultáneamente, además, se expresa el deseo de esta subjetividad por construir una familia. A partir de un sueño se describe la constitución de un hogar, particularmente, a través de objetos domésticos (cortinas, tacitas). Subercaseaux, 
finalmente, parece exponer que esta pulsión deseante no es más que solo literatura añorada, o sea, mera ficcionalidad en la que solo cabe la posibilidad, mas no la realidad que ella anhela. De manera, que asistimos más a un fracaso que a la victoria [del] travesti:

Soñó con casitas blancas, cortinitas blancas, tasitas ${ }^{10}$ blancas.

Digo que soñó, en un resabio literario de viejos hogares constituídos (48).

\section{Postal porteña: una coda}

Benjamín Subercaseaux, uno de los tantos "hermanos errantes" que pululan en la poesía chilena tiene el mérito de publicar el primer poemario homoerótico en la escena nacional despojado de los artilugios retóricos que ocultan los desvíos sexo-genéricos. El escritor no solo polemiza con los imperativos genéricos, promovidos por el Frente Popular, que obligan a los niños a seguir un dictamen heterosexualizador, sino que regocija al inventar la figura del cruisser, el familiar errado del flâneur, quien recorre la ciudad de Valparaíso en busca de placeres homoeróticos furtivos. Así, esta figura y la del niño homosexual complican y polemizan abiertamente con el ideologema familiar del Frente Popular, toda vez que este promueve una masculinidad hegemónica y una política reproductiva. Vistas así las cosas, si la producción literaria de Subercaseaux ha sido leída con hartazgo en el texto cultural chileno como epítome de la identidad nacional; pues habría también que desviarse de esa lectura y penetrar en los recovecos que el escritor nos invita a recorrer, pues allí hay cuerpos que claman por ser sacados del clóset de la literatura chilena.

\section{REFERENCIAS}

Amaro, Lorena. "Wacquez y sus precursores". La pose autobiográfica. Ensayos sobre narrativa chilena. Ediciones Universidad Alberto Hurtado, 2018.

Ayala, Matías. "Niños y cultura visual impresa durante la Unidad Popular chilena". Poéticas de lo viviente, lo animal y lo impersonal. Metales Pesados, 2020.

\footnotetext{
${ }^{10}$ La transcripción conserva la ortografía original del poemario.
} 
Balderston, Daniel. El deseo, enorme cicatriz luminosa. Ensayos sobre homosexualidades latinoamericanas. Beatriz Viterbo, 2004

Barba-Jacob, Porfirio. Poesía Completa. Recopilación y notas de Fernando Vallejo. Fondo de Cultura Económica, 2006.

Benjamin, Walter. Poesía y capitalismo: iluminaciones II. Taurus. 1998.

Chiuminatto, Pablo y Rodrigo del Río. "Imágenes del mar de Chile. Benjamín Subercaseaux e Ignacio Balcells, paralelo literario distante". TRANS- Revue de littérature générale et comparée, núm. 19, 2015.

Conell, Robert. "La organización social de la masculinidad". Masculinida/es. Poder y crisis, edición de Teresa Valdés y José Olavarría. Isis Internacional, 1997.

Darío, Rubén. Azul. Universidad de Valparaíso, 2013.

Edelman, Lee. No al futuro. La teoría queer y la pulsión de muerte, traducción de Javier Sáez y Adriana Baschuk. Madrid-Barcelona, 2014.

Foerster, Cristian. Tras la locura del cuerpo geográfico: reflexiones sobre la concepción de geografia y paisaje en Chile o la loca geografia de Benjamín Subercaseaux. Universidad de Chile, 2017.

García-Castro. "El cuerpo masculino visto por ojos latinoamericanos: Santa materia (1954) de Benjamín Subercaseaux y 'Vida ejemplar del esclavo y el señor' (1983) de Manuel Ramos Otero". Revista Iberoamericana, núm. 174, 1996, pp. 149-161.

Giorgi, Gabriel. Sueños de exterminio: homosexualidad y representación en la literatura argentina contemporánea. Beatriz Viterbo, 2004.

Halberstam, Jack. El arte queer del fracaso. Egales, 2018.

Hozven, Roberto. "Alegorías identitarias en cuatro ensayos chilenos". Anales de Literatura Chilena, núm. 2, 2001, pp. 207-219.

Jodorowsky, Alejandro. "Cuando ser gay no era un problema". El Periodista. Entrevistador: André Jouffe, 2003.

Lemebel, Pedro. Poco Hombre: crónicas escogidas. Universidad Diego Portales, 2013.

Molloy, Sylvia. Poses de fin de siglo. Desbordes del género en la modernidad. Eterna Cadencia, 2012.

Muñoz, José Esteban. Disidentifications: Queers of Color and the Performance of Politics. University of Minnesota, 1999.

Opazo, Cristián. "Cuerpos que no caben en la lengua." Cuadernos de Literatura, vol. 21, núm. 42, 2017, pp. 15-22.

Perlongher, Néstor. Prosa plebeya. Ensayos 1980-1992. Colihue, 1997.

Preciado, Paul. "Marcos Forever". Un apartamento en Urano. Crónicas del cruce. Anagrama, 2019.

Rosemblatt, Karin. "Por un hogar bien constituido. El Estado y su política familiar en los Frentes Populares". Disciplina y desacato. Construcción de Identidad en Chile, Siglos XIX y XX. Santiago, SUR/CEDEM, 1995.

Sedgwick, Eve. Epistemología del armario. Ediciones de la Tempestad, 1998.

Subercaseaux, Benjamín. Quince poemas directos. Nascimento, 1936.

---. Chile o una loca geografia. Editorial Universitaria, 2005. 